Article

\title{
Influence of Water-Miscible Organic Solvent on the Activity and Stability of Silica-Coated Ru Catalysts in the Selective Hydrolytic Hydrogenation of Cellobiose into Sorbitol
}

\author{
Tommy Haynes ${ }^{1}{ }^{\oplus}$, Sharon Hubert ${ }^{1}$, Samuel Carlier ${ }^{1}$, Vincent Dubois ${ }^{2}$ and \\ Sophie Hermans ${ }^{1, *(D)}$ \\ 1 IMCN Institute, MOST Division, Université Catholique de Louvain, 1 Place Louis Pasteur, B-1348 \\ Louvain-la-Neuve, Belgium; Tommy.Haynes@uclouvain.be (T.H.); Sharon.Hubert@uclouvain.be (S.H.); \\ Samuel.Carlier@uclouvain.be (S.C.) \\ 2 Department of Physical Chemistry and Catalysis, LABIRIS, 1 avenue Gryson, 1070 Brussels, Belgium; \\ vidubois@spfb.brussels \\ * Correspondence: sophie.hermans@uclouvain.be; Tel.: +32-10-472810; Fax: (+32)-10-472330
}

Received: 29 November 2019; Accepted: 16 January 2020; Published: 23 January 2020

\begin{abstract}
Ruthenium nanoparticles supported on carbon black were coated by mesoporous protective silica layers $\left(\mathrm{Ru} / \mathrm{CB} @ \mathrm{SiO}_{2}\right)$ with different textural properties $\left(\mathrm{S}_{\mathrm{BET}}: 280-390 \mathrm{~m}^{2} / \mathrm{g}\right.$, pore diameter: $3.4-5.0 \mathrm{~nm}$ ) and were tested in the selective hydrogenation of glucose into sorbitol. The influence of key parameters such as the protective layer pore size and the solvent nature were investigated. X-ray photoelectron spectroscopy (XPS) analyses proved that the hydrothermal stability was highly improved in ethanolic solution with low water content (silica loss: $99 \%$ in water and $32 \%$ in ethanolic solution). In this work, the strong influence of the silica layer pore sizes on the selectivity of the reaction (shifting from $4 \%$ to $68 \%$ by increasing the pores sizes from 3.4 to $5 \mathrm{~nm}$ ) was also highlighted. Finally, by adding acidic co-catalyst $\left(\mathrm{CB}-\mathrm{SO}_{3} \mathrm{H}\right)$, sorbitol was obtained directly through the hydrolytic hydrogenation of cellobiose (used as a model molecule of cellulose), demonstrating the high potential of the present methodology to produce active catalysts in biomass transformations.
\end{abstract}

Keywords: glucose; sorbitol; cellobiose; hydrothermal resistance; hydrolysis; hydrogenation; mesoporous silica; ruthenium; carbon

\section{Introduction}

For many years, the conversion of lignocellulosic biomass, an environmentally friendly and sustainable alternative resource to fossil fuels, into valuable chemicals and biofuels has drawn a lot of attention [1]. Therefore, cellulose, the main component of such biomass, has been widely studied and converted into various products such as hydrocarbons, oxygenated bio-oil, and sugar alcohols [2,3]. Enzymatic catalysis and fermentation allow breaking down cellulose and converting it into commodity chemicals [4]. Nevertheless, such biological processes suffer from limitations such as low efficiencies, limited scale of production, and narrow reaction conditions. Therefore, cellulose valorization transformations have been recently oriented toward solid heterogeneous catalysts. However, all these transformations are usually performed in aqueous media at higher temperature, implying the possible sintering of the catalytic active phase [5] and other deactivation processes.

Recently, our group has shown that the coverage of supported catalysts by a mesoporous silica layer could prevent the sintering of palladium nanoparticles dispersed on carbon black [6]. Nevertheless, it is well known that mesoporous silica materials such as MCM- 41 or SBA-15 are poorly 
stable under hydrothermal conditions [7]. Although post-functionalization with hydrophobic moieties or the incorporation of aluminum atoms are well-known methods to improve the hydrothermal stability of these materials [8-12], some drawbacks are often silent up. For instance, aluminum doping in a silica matrix alters the host material structural order, leading to a more amorphous material $[13,14]$. In order to override the possible structural properties' modifications of siliceous mesoporous materials and increase the catalysts' hydrothermal stability, catalytic transformations of cellulose could alternatively be performed in less damaging water-miscible organic solvents. In a recent review, it has been reported that organic solvents have also a great impact on the catalysts' performances in biomass conversion [15]. Moreover, considerable efforts were made to find innovative solvents that were potentially less toxic, more biocompatible, and had improved reaction rates and product selectivities [16,17]. For instance, Mellmer et al. have shown that the rate of cellobiose hydrolysis is strongly improved by using $\gamma$-valerolactone as solvent compared to conversion in aqueous media [18]. More recently, it has been proven that by tuning the water content in dimethyl sulfoxide, as well as the temperature and the reaction time, it is possible to perform a non-catalytic conversion of cellobiose into 5-hydroxymethyl-2-furaldehyde [19]. In addition to the solvent nature in which the catalytic reaction is carried out, it has been also proven that the mesoporous silica material type, and indirectly some parameters such as the wall thickness, have a great influence on the material hydrothermal stability [7].

In this context, we propose to cover heterogeneous catalysts (ruthenium on carbon black) by protective mesoporous silica layers with different structural properties and to evaluate their performances in the one-pot conversion of cellobiose into sorbitol in water-miscible organic solvents (Figure 1). Ruthenium being the most effective metal for this reaction has been selected as the active metal in the present study [20,21]. Two surfactants have been selected (P123 and hexadecyltrimethylammonium bromide, or CTAB) for the mesoporous layers formation. These should lead to coating layers presenting mesopores of different sizes. In the first part, the positive impact of using an organic polar solvent (such as ethanol) and the influence of the mesoporous protective layer type on the catalyst's activity and stability in the selective hydrogenation of glucose into sorbitol will be highlighted. In a second part, preliminary tests in the hydrolytic hydrogenation of cellobiose into sorbitol will be carried out. Cellulose is an insoluble polymer with a complex and robust crystalline structure; therefore, simple and soluble model molecules of cellulose such as cellobiose are often used in biomass conversion studies [22-24]. Sorbitol, which is the hydrogenated form of glucose, is targeted in this work because it is a platform molecule that is used for the production of value-added chemicals [25-28]. This reaction is also a good model system to study both hydrolysis and hydrogenation reactions in one pot (Figure 1). In short, the goal of this paper is to successfully prepare a protected catalyst and then prove that the underlying active phase is still accessible and the protecting layer can remain intact in catalytic testing conditions.

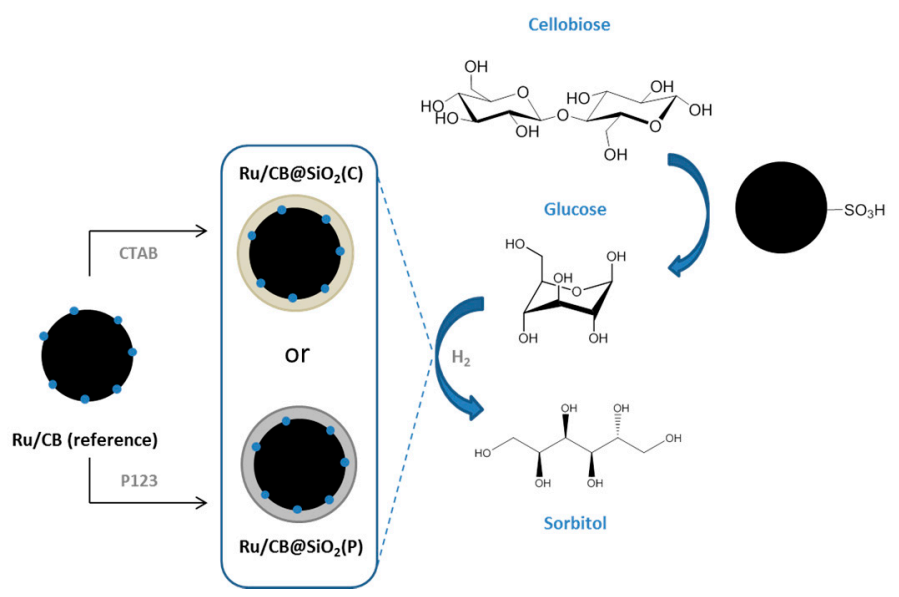

Figure 1. Overview of synthesized catalysts systems and catalytic applications tested. 


\section{Results and Discussion}

A starting $\mathrm{Ru} / \mathrm{CB}$ reference catalyst was prepared by homogeneous deposition-precipitation by using the urea method. This implies the slow precipitation of Ru hydroxide on the support followed by a reduction in $\mathrm{N}_{2} / \mathrm{H}_{2}$ atmosphere. Calcination was avoided because it is not compatible with the carbon support. Two different covered catalysts were subsequently prepared, using two different templating agents to create mesoporosity in the siliceous coating, namely $\mathrm{Ru} / \mathrm{CB} @ \mathrm{SiO}_{2}(\mathrm{C})$ when using CTAB and $\mathrm{Ru} / \mathrm{CB} @ \mathrm{SiO}_{2}(\mathrm{P})$ when using pluronic P123 as the templating agent. They were characterized by X-ray photoelectron spectroscopy (XPS), nitrogen physisorption, and SEM-EDX in order to identify the influence of their physicochemical characteristics on hydrothermal stability and activity in a biomass model reaction: the hydrolytic hydrogenation of cellobiose into sorbitol.

\subsection{XPS}

The surface atomic percentages in C1s, O1s, N1s, Si2p, and Ru3p measured by XPS for $\mathrm{Ru} / \mathrm{CB} @ S i O_{2}(\mathrm{C}), \mathrm{Ru} / \mathrm{CB} @ S i O_{2}(\mathrm{P})$ (covered catalysts) and $\mathrm{Ru} / \mathrm{CB}$ (reference catalyst) are given in Table 1 . As shown by these results, the covered materials exhibit a high level of oxygen and a lower carbon surface atomic percentage than the reference sample. Moreover, we can observe the emergence of a Si2p peak and a drastic fall of the Ru3p surface atomic percentage. All these observations confirm the silica layer deposition on a $\mathrm{Ru} / \mathrm{CB}$ catalyst, regardless of the surfactant type (neutral or anionic) or the preparation conditions (acidic or basic). It can also be noted that the XPS spectra display the Ru3 $p_{3 / 2}$ peak assigned to the metallic state (Figure S1 in the electronic supporting information). This result implies that the coverage of the catalysts surface by a silica layer does not affect the metal oxidation state. In the case of the covered sample using CTAB as a template $\left(\mathrm{Ru} / \mathrm{CB} @ S i{ }_{2}(\mathrm{C})\right)$, the higher level of nitrogen is imputed to residual surfactant in the smaller pores.

Table 1. X-ray photoelectron spectroscopy (XPS) analyses of reference and covered catalysts.

\begin{tabular}{cccccc}
\hline Sample & C1s & O1s & Si2p & N1s & Ru3p \\
\hline $\mathrm{Ru} / \mathrm{CB}$ & 96.0 & 3.4 & $/$ & 0.1 & 0.49 \\
$\mathrm{Ru} / \mathrm{CB} @ \mathrm{SiO}_{2}(\mathrm{C})$ & 47.2 & 35.6 & 15.2 & 1.0 & 0.09 \\
$\mathrm{Ru} / \mathrm{CB} @ \mathrm{SiO}_{2}(\mathrm{P})$ & 34.3 & 46.2 & 19.3 & 0.1 & 0.07 \\
\hline
\end{tabular}

\section{2. $\mathrm{N}_{2}$ Physisorption}

The covered samples have also been characterized by nitrogen physisorption (Figure 2) to evaluate the impact of surfactant type on the samples' textural properties. $\mathrm{Ru} / \mathrm{CB}_{\mathrm{SiO}}(\mathrm{C})$ exhibits a type IV (according to IUPAC) nitrogen adsorption-desorption isotherm with a $\mathrm{H} 1$ hysteris loop, which is typical of mesoporous materials with a narrow pore size distribution, as already proven in our recent paper with palladium nanoparticles as the active phase [6]. The isotherm obtained for $\mathrm{Ru} / \mathrm{CB}_{\mathrm{CSiO}}(\mathrm{P})$ is also characteristic of mesoporous materials, but the $\mathrm{H} 3$ type hysteresis loop obtained implies a material possessing a framework with a wide pore size distribution. Moreover, the hysteresis branches' positions for this material shifted toward higher pressures. Since the capillary condensation pressure is a function of the pore diameter $[29,30]$, the observed behavior shows that, as expected, covered material using pluronic surfactant (P123) displays larger pores than its CTAB counterpart. Indeed, the average pore diameter extracted from Barrett-Joyner-Halanda $(\mathrm{BJH})$ curves is higher for $\mathrm{Ru} / \mathrm{CB} @ \mathrm{SiO}_{2}(\mathrm{P})$ material $(5 \mathrm{~nm})$ than for $\mathrm{Ru} / \mathrm{CB} @ \mathrm{SiO}_{2}(\mathrm{C})$ material $(1.7 \mathrm{~nm}$ ) (Figure S2). As expected, the BJH curve also shows a very large pore size distribution for the $\mathrm{Ru} / \mathrm{CB} @ \mathrm{SiO}_{2}(\mathrm{P})$ catalyst. In the case of samples with narrow mesopores (such as $\mathrm{Ru} / \mathrm{CB} @ \mathrm{SiO}_{2}(\mathrm{C})$ ), it appears that the $\mathrm{BJH}$ method underestimates the sample pore size and that DFT (Density Functional Theory) analysis is more adapted to evaluate the pore size distribution [31]. Based on DFT analyses (Figure S2), $\mathrm{Ru} / \mathrm{CB} @ \mathrm{SiO}_{2}(\mathrm{C})$ material contains essentially mesopores $(3.4 \mathrm{~nm}$ ) with some micropores. The total pores' volume consistently corresponds to the sum of values calculated by the Dubinin and the BJH methods in both cases (see Figure S2). In consequence, 
the specific surface area of the $\mathrm{Ru} / \mathrm{CB} @ \mathrm{SiO}_{2}(\mathrm{P})$ sample is lower than that of the $\mathrm{Ru} / \mathrm{CB} @ S i \mathrm{~S}_{2}(\mathrm{C})$ material ( $280 \mathrm{~m}^{2} / \mathrm{g}$ versus $390 \mathrm{~m}^{2} / \mathrm{g}$, respectively), which is also a direct influence of the pore diameter increase. In both cases, the Brunauer-Emmett-Teller (BET) surface area has been greatly increased compared to the uncovered catalyst $\left(60 \mathrm{~m}^{2} / \mathrm{g}\right)$.

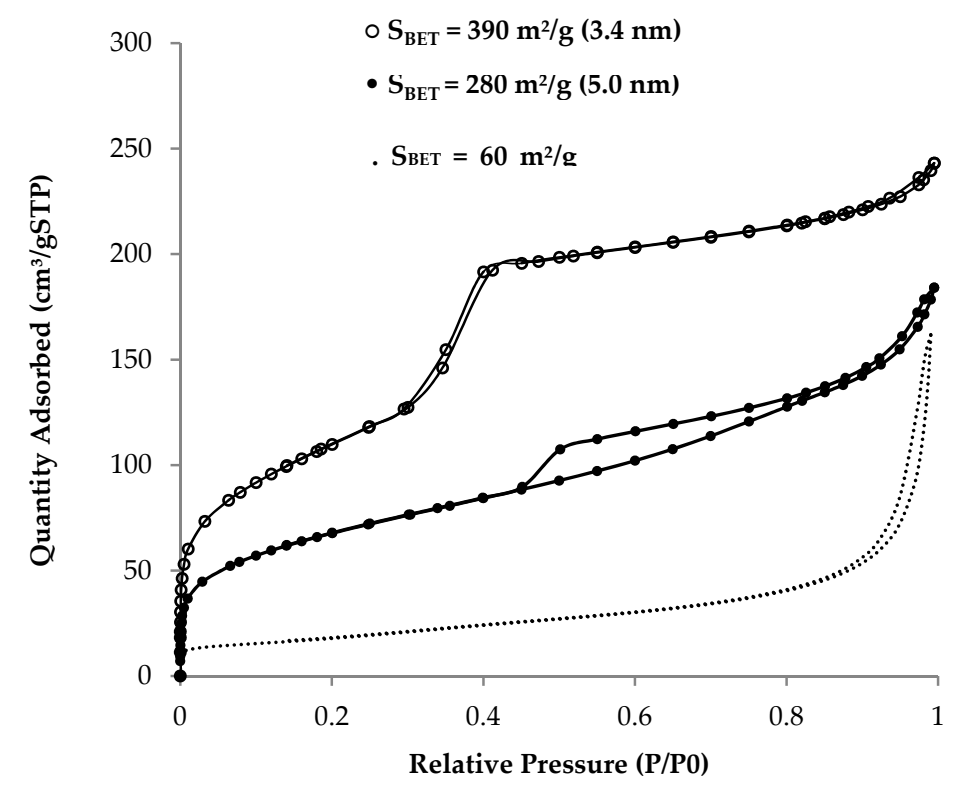

Figure 2. Nitrogen adsorption/desorption isotherms of $(\bigcirc) \mathrm{Ru} / \mathrm{CB} @ \mathrm{SiO}_{2}(\mathrm{C})$ and $(\bullet) \mathrm{Ru} / \mathrm{CB}_{\mathrm{SSiO}}(\mathrm{P})$ materials in comparison with the starting uncovered $\mathrm{Ru} / \mathrm{CB}$ (dotted line) catalyst.

\subsection{SEM-EDX}

Then, the covered catalysts have been analyzed by SEM-EDX (Energy-Dispersive X-ray) and $\mathrm{TEM}$, and compared to the $\mathrm{Ru} / \mathrm{CB}$ reference sample (Figure 3). As it can be seen on SEM images, after coverage of the ruthenium-supported catalyst (Figure 3b,c), the samples' morphology has been only slightly modified, meaning that the silica layers are thin and homogeneously deposited around the $\mathrm{Ru} / \mathrm{CB}$ catalysts. Moreover, EDX analyses (Figure S3) have revealed the presence of a distinguishable peak of silicon for covered samples, which is consistent with XPS analyses. The images also revealed that the silica layer is thicker in the case of the $\mathrm{Ru} / \mathrm{CB} @ \mathrm{SiO}_{2}(\mathrm{C})$ catalyst. Based on TEM images, all the samples show narrow particle size distribution at $\sim 1 \mathrm{~nm}$, confirming that the silica coating does not affect the ruthenium particle size. TEM images of samples without Ru were also recorded (Figure S4), which confirmed the above observations. 


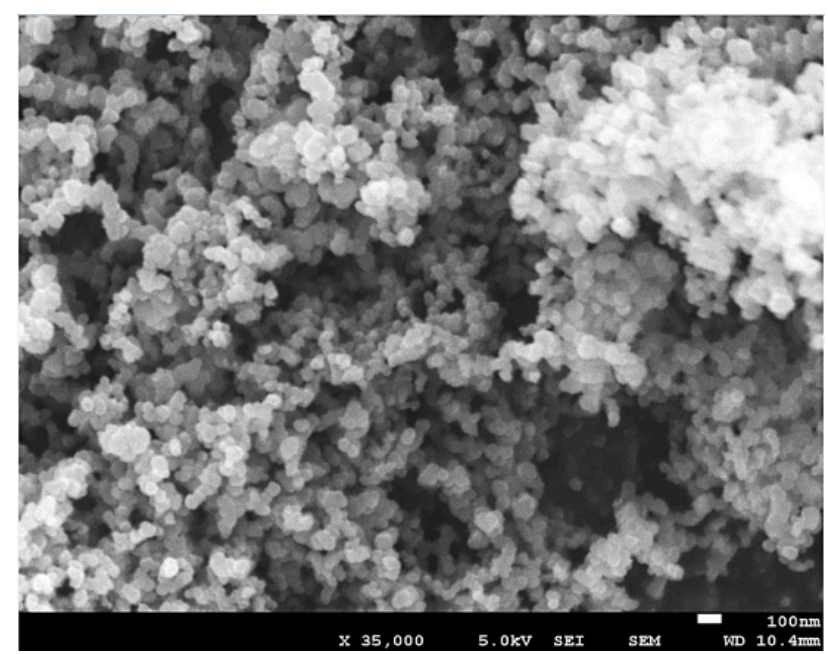

(a)

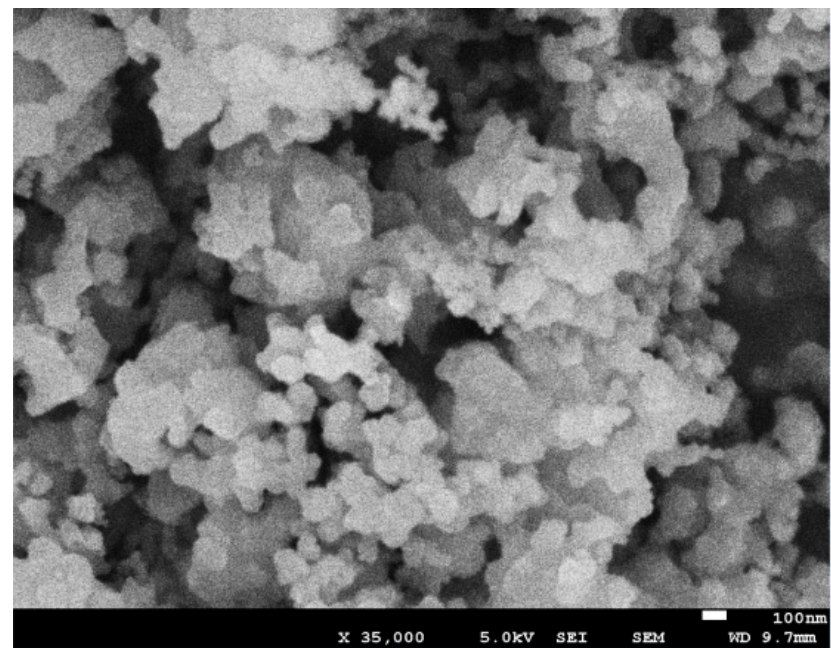

(b)

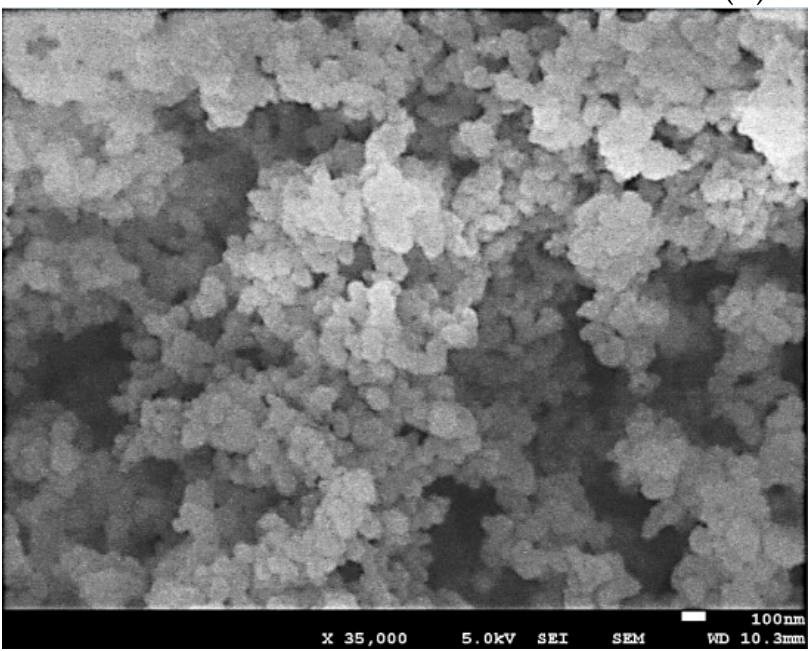

(c)
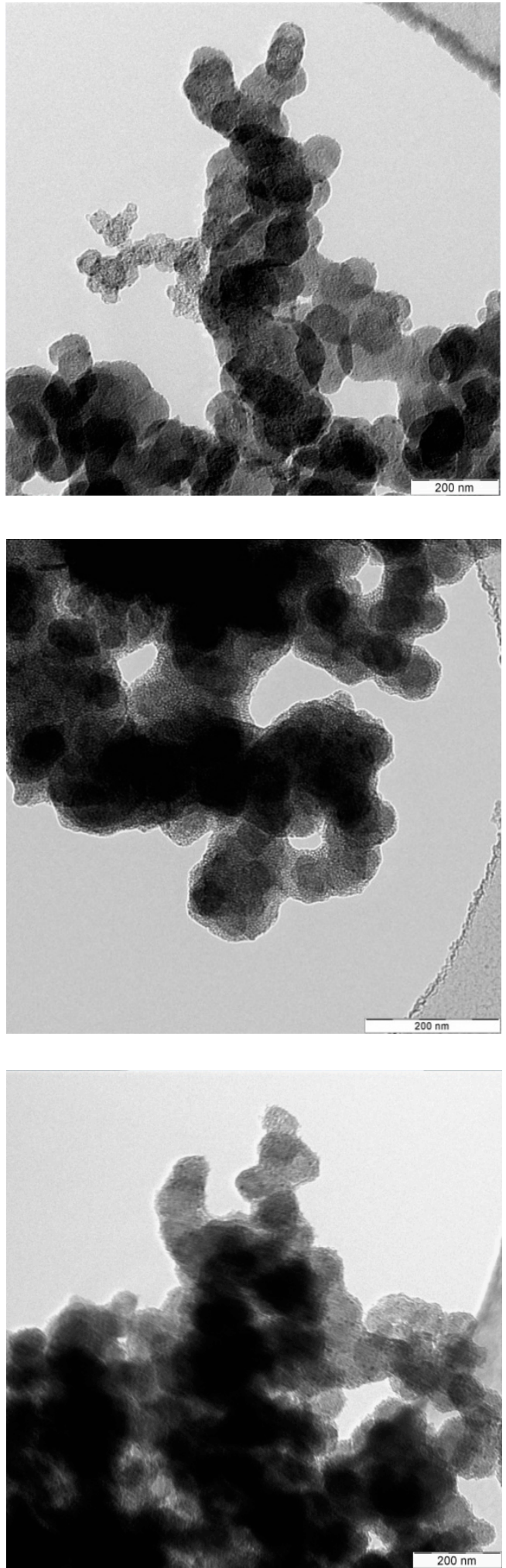

Figure 3. SEM/TEM images of (a) $\mathrm{Ru} / \mathrm{CB},(\mathbf{b}) \mathrm{Ru} / \mathrm{CB} @ \mathrm{SiO}_{2}(\mathrm{C})$, and (c) $\mathrm{Ru} / \mathrm{CB} @ \mathrm{SiO}_{2}(\mathrm{P})$.

\subsection{Catalytic Tests}

The catalytic performances of the synthesized catalysts were estimated in the hydrogenation of glucose into sorbitol. The glucose conversion and sorbitol selectivity are reported in Table 2. The reaction was first studied with a blank test in water (Entry 1). Although glucose is converted without 
catalyst (21\%), the selectivity toward sorbitol is quite low (2\%), leading essentially to fructose isomer. Since carbon black, which is used as support, could have a catalytic activity by itself, its catalytic performance was also evaluated (Entry 2): similar results to the blank were obtained. This test clearly shows that metallic nanoparticles are required to produce a high amount of sorbitol in this hydrogenation process. Indeed, when the reference (uncovered) $\mathrm{Ru} / \mathrm{CB}$ catalyst is used (Entry 3 ), the selectivity toward sorbitol is higher $(67 \%)$ together with a better activity (glucose conversion: $43 \%$ ). This result makes sense, since it is well known that ruthenium is one of the best active phases for glucose hydrogenation (see Table S3 for a comparison of normalized activity values with catalysts from the literature) [32-35]. The covered catalyst $\mathrm{Ru} / \mathrm{CB} @ \mathrm{SiO}_{2}(\mathrm{C})$ displays a conversion of $30 \%$ (Entry 4 ). According to elemental analyses (ICP) results (Table S1), this catalyst contains $1.8 \mathrm{wt} \%$ of ruthenium, while it was $2.3 \mathrm{wt} \%$ for the uncovered catalyst. Taking into account this dilution factor due to the addition of a silica layer (for the same engaged catalyst mass), we can calculate the activity as percentage conversion per mg of Ru engaged. The value obtained for $\mathrm{Ru} / \mathrm{CB} @ \mathrm{SiO}_{2}(\mathrm{C})$ is very close to the reference catalyst (41\%/mg and $47 \% / \mathrm{mg}$ respectively, compare Entries 4 and 3 ). This means that the silica layer does not prevent the diffusion of glucose to reach the ruthenium nanoparticles that are the active phase for this transformation, even in the presence of some residual surfactant in the porous network. Furthermore, as shown by XPS measurements (Table S2), this residual surfactant has been almost completely removed during the catalytic test. Nevertheless, the selectivity toward sorbitol is surprisingly low $(4 \%)$, indicating that the silica protective layer could have an impact on the reaction selectivity. Particles size and support effects can be discarded. Indeed, the ruthenium deposition and the carbonaceous support are the same as the reference catalyst, and the coverage methodology does not affect the particles' size, as already demonstrated in [6] and in TEM images. We believe that because the pores' sizes are below the limit for easy diffusion, the sugar molecules enter the pores with steric constraints and probably do not have a complete rotational degree of freedom (the concept of shape selectivity known for zeolites), with a strong effect on the selectivity. Indeed, based on the seminal paper by Beck and Schultz [36], the restrictions of glucose diffusion through the silica layers can be calculated, considering $3.4 \mathrm{~nm}$ and $5.0 \mathrm{~nm}$ as the pore diameters of our materials and $0.88 \mathrm{~nm}$ for the molecular diameter of glucose. This reveals that the mobility of glucose through the mesoporous channels of $\mathrm{Ru} / \mathrm{CB} @ \mathrm{SiO}_{2}$ catalysts is respectively $46 \%$ and $30 \%$ (for $3.4 \mathrm{~nm}$ and $5.0 \mathrm{~nm}$ pores) lower than its mobility in free solution.

Table 2. Conversion and selectivity for the hydrogenation of glucose after $2 \mathrm{~h}$ reaction at $150^{\circ} \mathrm{C}$.

\begin{tabular}{cccccc}
\hline Entry & Sample & Solvent & $\begin{array}{c}\text { Glucose } \\
\text { Conversion (\%) }\end{array}$ & $\begin{array}{c}\text { Activity } \\
\text { (\%/mg) }\end{array}$ & $\begin{array}{c}\text { Sorbitol } \\
\text { Selectivity (\%) }\end{array}$ \\
\hline 1 & $\mathrm{Blank}$ & $\mathrm{H}_{2} \mathrm{O}$ & 21 & $/$ & 2 \\
2 & $\mathrm{CB}$ & $\mathrm{H}_{2} \mathrm{O}$ & 16 & $/$ & 7 \\
3 & $\mathrm{Ru} / \mathrm{CB}$ & $\mathrm{H}_{2} \mathrm{O}$ & 43 & 47 & 67 \\
4 & $\mathrm{Ru} / \mathrm{CB} @ \mathrm{SiO}_{2}(\mathrm{C})$ & $\mathrm{H}_{2} \mathrm{O}$ & 30 & 41 & 4 \\
$5^{2}$ & $\mathrm{Ru} / \mathrm{CB} @ \mathrm{SiO}_{2}(\mathrm{C})-\mathrm{HT}$ & $\mathrm{H}_{2} \mathrm{O}$ & 41 & 45 & 68 \\
6 & $\mathrm{Blank}$ & $\mathrm{EtOH} / \mathrm{H}_{2} \mathrm{O}$ & 26 & $/$ & 1 \\
7 & $\mathrm{Ru} / \mathrm{CB}$ & $\mathrm{EtOH} / \mathrm{H}_{2} \mathrm{O}$ & 92 & 100 & 74 \\
8 & $\mathrm{Ru} / \mathrm{CB} @ \mathrm{CiO}_{2}(\mathrm{C})$ & $\mathrm{EtOH} / \mathrm{H}_{2} \mathrm{O}$ & 69 & 94 & 4 \\
9 & $\mathrm{Ru} / \mathrm{CB} @ \mathrm{SiO}_{2}(\mathrm{P})$ & $\mathrm{EtOH} / \mathrm{H}_{2} \mathrm{O}$ & 43 & 82 & 58 \\
$10^{3}$ & $\mathrm{Ru} / \mathrm{CB} @ \mathrm{SiO}_{2}(\mathrm{P})$ & $\mathrm{EtOH} / \mathrm{H}_{2} \mathrm{O}$ & 50 & 81 & 66 \\
\hline
\end{tabular}

${ }^{1}$ Normalized activity $=$ glucose conversion per mg of ruthenium engaged. ${ }^{2}$ Treated in hot water for $24 \mathrm{~h}$.

3 Second run.

Moreover, after the catalytic test, XPS analyses have revealed that $99 \%$ of Si has been lost by the known desilication process in water (Table S2) [37]. As mentioned in the introduction, it is well established in the literature that silica materials are poorly stable in hydrothermal conditions [7]. Desilication is a slow phenomenon leading to a progressive loss of the silica layer in solution. So, during the whole catalytic test, the $\mathrm{Ru} / \mathrm{CB} @ \mathrm{SiO}_{2}(\mathrm{C})$ catalyst is constantly covered by a silica layer that only decreases in thickness. Hence, the accessibility remains, and the selectivity is controlled by 
shape selectivity at all times, very differently from the uncovered catalyst. In order to confirm this hypothesis, we have treated the $\mathrm{Ru} / \mathrm{CB}_{\mathrm{SSiO}}(\mathrm{C})$ in hot water for $24 \mathrm{~h}$ (to completely remove the silica layer). This "treated" catalyst has been then re-evaluated in the glucose hydrogenation reaction (Entry 5). Both its conversion and selectivity toward glucose are the same as that of the reference (uncovered) catalyst $(\mathrm{Ru} / \mathrm{CB})$, which corroborates our hypothesis.

Consequently, the next tests were carried out in an ethanol-water mixture $(110: 10, \mathrm{v} / \mathrm{v})$ to minimize the silica losses. A new blank test has been performed in those conditions that shows relatively low activity and selectivity as in pure water (Entry 6). Astonishingly, in the case of the reference (uncovered) catalyst (Entry 7), the conversion has drastically increased (92\%), while the selectivity is quite stable $(74 \%)$. In the same way, the $\mathrm{Ru} / \mathrm{CB} @ \mathrm{SiO}_{2}(\mathrm{C})$ covered sample shows higher conversion than in pure water $(69 \%)$, but still a very low selectivity (4\%) (Entry 8). Therefore, it appears that the solvent nature has an effective impact on the catalyst activity for this reaction, which was never reported in the literature, to the best of our knowledge. As expected, the stability of our catalysts has been also improved in an ethanol-water mixture with a much lower silicon loss (32\% loss of the initial Si content according to XPS measurement compared to $99 \%$ loss in pure water, see Table S2). Moreover, the water-miscible organic solvent allows totally removing the residual surfactant. An additional TGA (Thermogravimetric Analysis) measurement of $\mathrm{Ru} / \mathrm{CB} @ \mathrm{SiO}_{2}(\mathrm{C})$ after the catalytic test in ethanol/water media was carried out (see Figure S5). In order to clearly identify the temperature at which the CTAB is decomposed, a reference sample consisting of $\mathrm{CTAB}$ deposited on carbon black $(\mathrm{CB})$ has been also analyzed. As can be noticed, CTAB is decomposed at $250{ }^{\circ} \mathrm{C}$ under air. This mass loss does not appear in the case of $\mathrm{Ru} / \mathrm{CB} @ \mathrm{SiO}_{2}(\mathrm{C})$ catalyst. These results clearly prove that any remaining $\mathrm{CTAB}$ surfactant is also totally removed during the catalytic test in organic media and does not prevent glucose from reaching the underlying ruthenium nanoparticles.

In the case of $\mathrm{Ru} / \mathrm{CB} @ \mathrm{SiO}_{2}(\mathrm{P})$ material (Entry 9), the selectivity toward the desired product is much better $(58 \%)$, which can be attributed to the larger pore diameter. As discussed above, the shape selectivity effect will be stronger for the smaller pores' layer. However, the observed difference in glucose conversion, in comparison with the reference catalyst (compare Entry 7 with 9), cannot be totally explained by the silica dilution factor as above (normalized activity calculated according to ruthenium mass engaged is $82 \% / \mathrm{mg}$ in this case). Therefore, it would appear that some of the ruthenium nanoparticles are completely covered by the silica and consequently unreachable. In addition, the large pore distribution of this catalyst also implies the presence of micropores (see Figure S2), which could prevent the access to some ruthenium nanoparticles and explain the slight decrease in normalized activity. Nevertheless, the loss of $\mathrm{Si}$ after the catalytic test decreased even further (18\% according to XPS measurement, see Table S2). This improvement in stability is not surprising. Indeed, Zhao et al. have already shown that mesoporous materials such as SBA-15, with larger pores, were more stable than MCM-41 under hydrothermal conditions [38]. More recently, Pollock et al. found that SBA-15 treated in liquid water at $155^{\circ} \mathrm{C}$ lost its secondary pore network by a complete closure [39]. In our case, when $\mathrm{Ru} / \mathrm{CB} @ \mathrm{SiO}_{2}(\mathrm{P})$ catalyst was reused for a second run (Entry 10), the conversion and selectivity are quite similar (if not better) than in the first run. The slight increase could be ascribed to relatively higher Ru loading due to slight Si loss (18\% measured by XPS, as discussed above). In comparison, the uncovered $\mathrm{Ru} / \mathrm{CB}$ catalyst, upon recycling, loses $16 \%$ activity (glucose conversion), but the selectivity is maintained. Moreover, the covered catalyst still exhibits a high specific surface area $\left(227 \mathrm{~m}^{2} / \mathrm{g}\right)$, the same isotherm curve shape, and similar pore size distribution compared with the fresh catalyst (Figure S6). These results imply that our material (more specifically the silica layer) is stable under these conditions. They also prove that the underlying ruthenium nanoparticles are still accessible and consequently that the pore network is still open.

The best-performing covered catalyst, namely $\mathrm{Ru} / \mathrm{CB} @ \mathrm{SiO}_{2}(\mathrm{P})$, was finally tested in a model reaction of cellulose valorization: the catalytic transformation of cellobiose into sorbitol in one pot. Kinetic modeling has shown that hydrolysis is the rate-limiting step for the hydrolytic hydrogenation of cellobiose (or cellulose) to sorbitol (110-115 KJ/mol for the hydrolysis of cellobiose) [19,40]. Therefore, 
this step is a highly demanding reaction that usually requires strong acid sites irrespective of the reaction pathway to produce sorbitol, as shown in Figure 4.

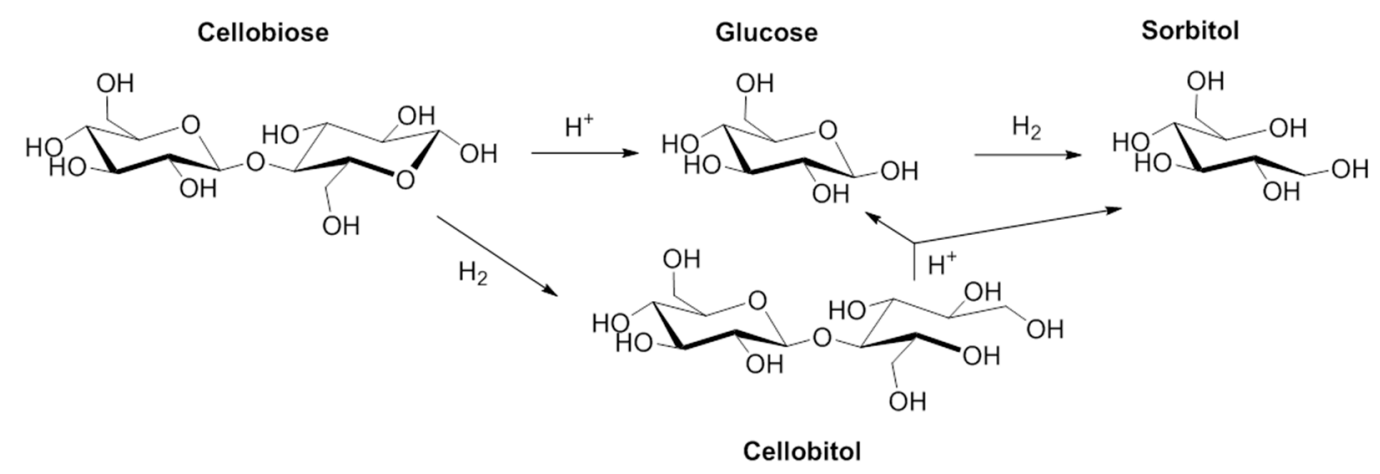

Figure 4. Reaction pathways for cellobiose conversion to sorbitol.

Nevertheless, as shown in Table 3, when the hydrolysis of cellobiose was performed without catalyst in pure water (Entry 1), glucose was obtained. Therefore, the hydrolytic hydrogenation of cellobiose in organic medium in the presence of our covered catalysts was performed with small fractions of water (Entry 2-4) to ensure the production of glucose without damaging the silica layer. Unfortunately, no glucose or sorbitol were obtained after $2 \mathrm{~h}$ of reaction with $\mathrm{Ru} / \mathrm{CB} @ \mathrm{SiO}_{2}(\mathrm{P})$ catalyst (Entry 2), meaning that the small volume fraction of water $\left(\mathrm{X}_{\mathrm{w}}=8 \%\right)$ introduced is not enough to allow the hydrolysis reaction. By increasing this fraction to $X_{w}=33 \%$ (Entry 3 ) and $X_{w}=50 \%$ (Entry $4)$, the results remained unchanged. However, cellobiose is in the meantime mainly converted into cellobitol (up to $42 \%$ ). Usually, it is known that the hydrolytic hydrogenation of cellobiose (or cellulose) to sorbitol occurs via the hydrolysis of glycosidic bonds followed by the hydrogenation of glucose into sorbitol. Nevertheless, as proven by Palkovits et al. [40], the cellobiose conversion could also proceed through an alternative pathway: the hydrogenation of a $\mathrm{C}-\mathrm{O}$ bond on one of the glucose rings, leading to cellobitol and consecutive hydrolysis to sorbitol and glucose (Figure 4). This result proves again that our material, thanks to its large pores, allows the diffusion of larger biomolecules such as cellobiose through the silica layer to reach the underlying metallic nanoparticles that are the active phase for this transformation.

Table 3. Conversion and selectivity for the hydrogenation and hydrolysis of cellobiose at $150{ }^{\circ} \mathrm{C}$ for $2 \mathrm{~h}$ under 30 bars of pure hydrogen.

\begin{tabular}{|c|c|c|c|c|c|c|c|}
\hline Entry & Sample & $\begin{array}{c}\mathrm{H}_{2} \mathrm{O} / \mathrm{EtOH} \\
(v / v)\end{array}$ & $\begin{array}{c}\text { Cellobiose } \\
\text { Conversion } \\
(\%)\end{array}$ & $\begin{array}{c}\text { Glucose } \\
\text { Selectivity } \\
(\%)\end{array}$ & $\begin{array}{c}\text { Ethyl } \\
\text { Glucopyr. } \\
\text { Selectivity } \\
\text { (\%) }\end{array}$ & $\begin{array}{c}\text { Cellobitol } \\
\text { Selectivity } \\
(\%)\end{array}$ & $\begin{array}{c}\text { Sorbitol } \\
\text { Selectivity } \\
(\%)\end{array}$ \\
\hline 1 & blank & $120 / 0$ & 44 & 14 & 0 & 0 & 0 \\
\hline 2 & $\mathrm{Ru} / \mathrm{CB} @ \mathrm{SiO}_{2}(\mathrm{P})$ & $10 / 110$ & 43 & 0 & 0 & 30 & 0 \\
\hline 3 & $\mathrm{Ru} / \mathrm{CB} @ S \mathrm{O}_{2}(\mathrm{P})$ & $40 / 80$ & 38 & 0 & 0 & 27 & 0 \\
\hline 4 & $\mathrm{Ru} / \mathrm{CB} @ \mathrm{SiO}_{2}(\mathrm{P})$ & $60 / 60$ & 45 & 0 & 0 & 42 & 0 \\
\hline 5 & $\begin{array}{c}\mathrm{Ru} / \mathrm{CB} @ \mathrm{SiO}_{2}(\mathrm{P}) \\
+\mathrm{CB}-\mathrm{SO}_{3} \mathrm{H}\end{array}$ & $10 / 110$ & 69 & 13 & 19 & 6 & 2 \\
\hline $6^{1}$ & $\begin{array}{c}\mathrm{Ru} / \mathrm{CB} @ \mathrm{SiO}_{2}(\mathrm{P}) \\
+\mathrm{CB}-\mathrm{SO}_{3} \mathrm{H}\end{array}$ & $10 / 110$ & 94 & 20 & 32 & 0 & 8 \\
\hline
\end{tabular}

Finally, an acidic material consisting of sulfonic acid moieties grafted on carbon black $\left(\mathrm{CB}-\mathrm{SO}_{3} \mathrm{H}\right)$ [41] was added (Entry 5) in the catalytic medium. Sulfonic acid functions are often used for cellobiose/cellulose hydrolysis reactions [42-45]. As can been seen, after $2 \mathrm{~h}$, glucose is produced. This result confirms that acidic sites are essential to hydrolyse cellobiose in organic medium. Another compound has been also detected, which could be attributed to ethyl glucopyranoside. Experimental and theoretical studies have shown that this cellulose hydrolysis mechanism involves the glycosidic oxygen protonation (Figure 5) [46]. In this mechanism, a cyclic oxonium ion is formed 
and reacts with water to reestablish the anomeric center and regenerate $\mathrm{H}_{3} \mathrm{O}^{+}$species. Based on this mechanism, a solvent such as ethanol could easily react with the second intermediate to produce ethyl glucopyranoside (Figure 5). More importantly, we have also observed in this test (Entry 5) the production of cellobitol and sorbitol. This means that the ruthenium nanoparticles of the covered catalyst are still active and accessible. Recently, Soisangwan et al. have shown that the conversion of cellobiose raised with the increasing ethanol concentration in subcritical water (liquid water between 100 and $374{ }^{\circ} \mathrm{C}$ under high pressure [usually from 1 to $6 \mathrm{MPa}$ ]) [47]. However, they also demonstrated that ethanol promotes the isomerization of disaccharides at the expense of a hydrolysis reaction [48]. In our case, isomerization is limited. Indeed, only a small amount of isomers such as fructose or cellobiulose are observed, demonstrating the good performances of our combined catalysts. Other (undetected) by-products such as 5-(hydroxymethyl)furfural (HMF) are formed as expected in this case. By increasing the amount of covered catalyst engaged (Entry 6), the conversion and the sorbitol selectivity are further improved. This also impacts positively the hydrolysis step, as expected. All these preliminary results in the hydrolytic hydrogenation of cellobiose show the high potential of the as-prepared protected catalyst in biomass valorization.

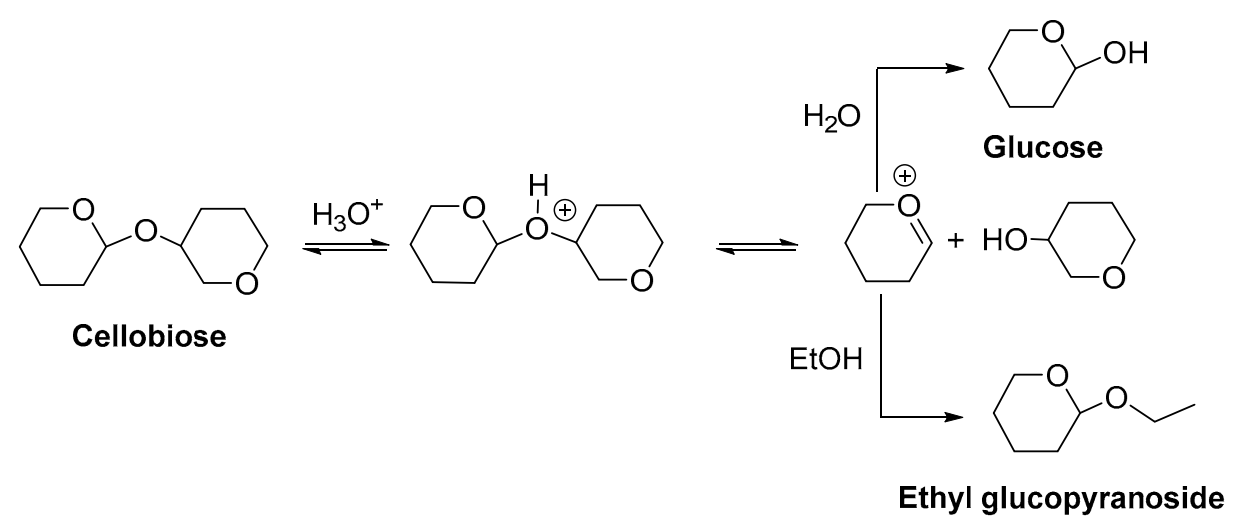

Figure 5. Mechanism of acid hydrolysis of glycosidic bonds in water or organic medium (hydroxyl groups have been voluntary omitted for more clarity).

\section{Materials and Methods}

\subsection{Reagents}

The carbon black support (CB) was received as 250G type from IMERYS GRAPHITE \& CARBON. Hexadecyltrimethylammonium bromide (CTAB, 95\%), (3-aminopropyl) trimethoxysilane (APTES, $99 \%$ ), tetraethyl orthosilicate (TEOS, $>98 \%$ ), thionyl chloride $\left(\mathrm{SOCl}_{2},>99 \%\right)$, Ruthenium(III) chloride hydrate, pluronic P123, sulfanilic acid (99\%), and isopentyl nitrite (96\%) were purchased from Sigma Aldrich and used as received. A commercial ultrasonic cleaner (VWR) was used for sonication.

\subsection{Syntheses}

\subsubsection{Synthesis of $\mathrm{Ru} / \mathrm{CB}$ Catalyst (Reference)}

A non-covered $\mathrm{Ru} / \mathrm{CB}$ catalyst used as a reference has been synthesized by an urea assisted deposition-precipitation procedure [49]. First, $600 \mathrm{mg}$ of urea were dissolved in $300 \mathrm{~mL}$ of distilled water. Then, $1 \mathrm{~g}$ of $\mathrm{CB}$ was added, and the mixture was stirred for $15 \mathrm{~min}$. Then, $73.5 \mathrm{mg}$ of $\mathrm{RuCl}_{3}(3.5$ wt $\% \mathrm{Ru}$ ) were added. After stirring for $1 \mathrm{~h}$, the mixture was heated to $120^{\circ} \mathrm{C}$ for $1 \mathrm{~h}$, cooled down to room temperature, and stirred overnight. Next, the solid was filtered out, washed with $250 \mathrm{~mL}$ of distilled water, and dried at $100{ }^{\circ} \mathrm{C}$ overnight. Finally, the catalyst was submitted to a thermal treatment under reducing atmosphere in a tubular oven STF 16/450 from CARBOLITE. The sample was placed into porcelain combustion boats and heated during $2 \mathrm{~h}$ at $600^{\circ} \mathrm{C}$ (heating ramp and cooling ramp: $100^{\circ} \mathrm{C} / \mathrm{h}$ ) under a stream of $\mathrm{N}_{2} / \mathrm{H}_{2}(95: 5)$. 


\subsubsection{Synthesis of $\mathrm{Ru} / \mathrm{CB} @ \mathrm{SiO}_{2}(\mathrm{C})$}

The synthesis of nanoparticles supported on carbon black (CB) covered by a thin mesoporous silica layer has been previously described for palladium catalysts [6]. In this study, it has been adapted for ruthenium as follows. First, $2 \mathrm{~g}$ of carbon black (CB) were introduced in a $250 \mathrm{~mL}$ round-bottom flask containing $100 \mathrm{~mL}$ of toluene. Then, $6 \mathrm{~mL}$ of $\mathrm{SOCl}_{2}$ were added, and the mixture was heated for $5 \mathrm{~h}$ under reflux. Then, it was filtered out and extensively washed with toluene $(500 \mathrm{~mL})$. The resulting material $(\mathrm{CB}-\mathrm{Cl})$ was dried overnight under vacuum at $100^{\circ} \mathrm{C}$. Then, $1 \mathrm{~g}$ of $\mathrm{CB}-\mathrm{Cl}$ was introduced in a $250 \mathrm{~mL}$ round-bottom flask containing $100 \mathrm{~mL}$ of dichloromethane. Then, $1 \mathrm{~mL}$ of APTES was added, and the mixture was stirred for $24 \mathrm{~h}$ at room temperature. Finally, the material (CB-APTES) was filtered out, washed with dichloromethane $(250 \mathrm{~mL})$ and methanol $(250 \mathrm{~mL})$, and dried overnight under vacuum at $100{ }^{\circ} \mathrm{C}$. Then, ruthenium nanoparticles were deposited on CB-APTES ( $\left.1 \mathrm{~g}\right)$ by a urea-assisted procedure, using the same synthesis conditions as described above, by engaging $73.5 \mathrm{mg}$ of $\mathrm{RuCl}_{3}(3.5 \mathrm{wt} \% \mathrm{Ru})$. After a thermal treatment for $2 \mathrm{~h}$ at $600{ }^{\circ} \mathrm{C}$ under reducing atmosphere $\left(\mathrm{N}_{2} / \mathrm{H}_{2}\right.$, 95:5), $0.250 \mathrm{~g}$ of $\mathrm{Ru} / \mathrm{CB}$-APTES was introduced in a $100 \mathrm{~mL}$ round-bottom flask containing $25 \mathrm{~mL}$ of distilled water. Then, $10 \mathrm{~mL}$ of $\mathrm{NaOH}(0.1 \mathrm{M})$ were added, and the mixture was sonicated for $10 \mathrm{~min}$. To this suspension, $0.571 \mathrm{~g}$ of CTAB was added, and the solution was heated at $60^{\circ} \mathrm{C}$. Then, $0.7 \mathrm{~mL}$ of TEOS was added dropwise within $30 \mathrm{~min}$. This suspension was further stirred for $3 \mathrm{~h} 30 \mathrm{~min}$, then charged into a propylene bottle, which was closed tightly and heated at $100^{\circ} \mathrm{C}$ for 3 days. The product was filtered out, washed with ethanol $(250 \mathrm{~mL})$, and dried at $100{ }^{\circ} \mathrm{C}$ overnight. The CTAB template was removed by refluxing the solid material $\left(\mathrm{Ru} / \mathrm{CB} @ S \mathrm{O}_{2}\right)$ for $24 \mathrm{~h}$ in ethanol.

\subsubsection{Synthesis of $\mathrm{Ru} / \mathrm{CB} @ \mathrm{SiO}_{2}(\mathrm{P})$}

The synthesis of $\mathrm{Ru} / \mathrm{CB} @ S \mathrm{O}_{2}(\mathrm{P})$ was achieved following the procedure described above to prepare $\mathrm{Ru} / \mathrm{CB} @ \mathrm{SiO}_{2}(\mathrm{C})$ with two modifications. First, during the sol-gel process with TEOS as a precursor, $35 \mathrm{~mL}$ of $\mathrm{HCl} 0.3 \mathrm{M}$ was used instead of a $\mathrm{NaOH}(0.1 \mathrm{M}) /$ water mixture. Second, $120 \mathrm{mg}$ of pluronic P123 were added instead of $571 \mathrm{mg}$ CTAB.

\subsubsection{Synthesis of $\mathrm{CB}-\mathrm{SO}_{3} \mathrm{H}$}

The supports functionalization was carried out by a diazonium coupling method [41]. Typically, $1 \mathrm{~g}$ of carbon black was dispersed in $60 \mathrm{~mL}$ of distilled water. Then, $1.5 \mathrm{~g}$ of sulfanilic acid were added, and the suspension was stirred at $70{ }^{\circ} \mathrm{C}$ during $10 \mathrm{~min}$. Afterwards, $1.2 \mathrm{~mL}$ of isopentyl nitrite were added at $30^{\circ} \mathrm{C}$, and the mixture was stirred during $16 \mathrm{~h}$. Then, it was filtered out and washed with distilled water and ethanol. The resulting material, $\mathrm{CB}-\mathrm{SO}_{3} \mathrm{H}$, was dried overnight at $100{ }^{\circ} \mathrm{C}$.

\subsection{Characterizations}

The solid materials were characterized by X-ray photoelectron spectroscopy (XPS), scanning electron microscopy (SEM), transmission electron microscopy (TEM), elemental analyses (ICP), and $\mathrm{N}_{2}$ physisorption.

XPS analyses were carried out at room temperature with an SSI-X-probe (SSX 100/206) photoelectron spectrometer from Surface Science Instruments (USA), equipped with a monochromatized microfocus Al X-ray source. Samples were stuck onto small sample holders with double-face adhesive tape and then placed on an insulating ceramic carousel (Macor ${ }^{\circledR}$, Switzerland). Charge effects were avoided by placing a nickel grid above the samples and using a flood gun set at $8 \mathrm{eV}$. The binding energies were calculated with respect to the $\mathrm{C}-(\mathrm{C}, \mathrm{H})$ component of the $\mathrm{C} 1 \mathrm{~s}$ peak fixed at $284.8 \mathrm{eV}$. Data treatment was performed using the CasaXPS program (Casa Software Ltd., UK). The peaks were decomposed into a sum of Gaussian/Lorentzian (85/15) after the subtraction of a Shirley-type baseline.

SEM images were obtained on a Field Emission Scanning Electron Microscope JEOL JSM-7600 F, equipped with an energy dispersive $X$-ray system. The powder samples were pressed onto double-face adhesive carbon tape adhered to an aluminum sample holder. Images were acquired at different 
acceleration voltages ranging between 3 and $15 \mathrm{keV}$, using an InLens detector. TEM images were obtained on an LEO 922 Omega Energy Filter Transmission Electron Microscope operating at $120 \mathrm{kV}$. The samples were suspended in hexane under ultrasonic treatment. A drop of the suspension was deposited on a holey carbon film supported on a copper grid (Holey Carbon Film 300 Mesh Cu, Electron Microscopy Sciences), which was dried overnight under vacuum at room temperature, before introduction in the microscope.

The elemental analyses $(\mathrm{C}, \mathrm{H}, \mathrm{N}, \mathrm{Si}$, and $\mathrm{Ru}$ ) were carried out by MEDAC Ltd., UK by microgravimetry for $\mathrm{C}, \mathrm{H}, \mathrm{N}$ (direct measure) and by ICP after acid digestion for Si and Ru.

The pore texture of the covered catalysts was characterized by nitrogen adsorption-desorption isotherms. The measures were achieved at $77 \mathrm{~K}$ by using a Micromeritics ASAP 2020 analyzer. Before analysis, the samples $(0.02-0.10 \mathrm{~g})$ were degassed for $2 \mathrm{~h}$ at $200^{\circ} \mathrm{C}$ with a heating rate of $10^{\circ} \mathrm{C} / \mathrm{min}$ under 0.133 Pa pressure. The analysis of the isotherms provided specific surface areas calculated with the Brunauer-Emmett-Teller (BET) equation, SBET. The pore volume, Vp, of the samples and the pores' average diameter were calculated using the Barrett-Joyner-Halanda (BJH) and DFT models.

\subsection{Catalytic Tests}

The tests were carried out in a $250 \mathrm{~mL}$ stainless steel Parr autoclave. First, $1 \mathrm{~g}$ of cellobiose (or glucose) was added to $40 \mathrm{mg}$ of catalyst in $120 \mathrm{~mL}$ of $\mathrm{mQ}$ (milliQ) water (or a mixture of ethanol $/ \mathrm{mQ}$ water). Then, the autoclave was sealed, and the system was purged three times with nitrogen and once with pure hydrogen. Once the desired temperature has been reached $\left(150^{\circ} \mathrm{C}\right), 30$ bars of hydrogen were introduced, and the mixture was stirred at $1700 \mathrm{rpm}$ for $2 \mathrm{~h}$. Then, the system was cooled down to room temperature, and the solution was filtrated. Then, the filtrate was diluted to $250 \mathrm{~mL}$ with $\mathrm{mQ}$ water and analyzed by HPLC.

HPLC analyses were performed with a Waters system equipped with a Waters 2414 refractive index (RI) detector (detector temperature $=30^{\circ} \mathrm{C}$ ). The column used is an Aminex HPX $87 \mathrm{C}$ column, with $\mathrm{mQ} \mathrm{H}_{2} \mathrm{O}\left(18 \mathrm{M} \Omega . \mathrm{cm}\right.$ at $\left.25^{\circ} \mathrm{C}\right)$ as the eluent, a flux of $0.5 \mathrm{~mL} / \mathrm{min}$, a column temperature of $85^{\circ} \mathrm{C}$, and $25 \mu \mathrm{L}$ of injected volume.

\section{Conclusions}

In the present work, catalysts covered by protective silica layers with very different morphologies and textural properties have been prepared. These catalysts have been fully characterized by XPS, SEM, ICP, and $\mathrm{N}_{2}$ physisorption. The presence of the layer was confirmed by XPS and SEM/TEM. Two different templates were used, and both gave mesoporous silica but with different pore sizes: $3.4 \mathrm{~nm}$ when using $\mathrm{CTAB}$ and $5 \mathrm{~nm}$ when using pluronic P123. Moreover, the silica layer was thicker in the former case $\left(\mathrm{Ru} / \mathrm{CB} @ \mathrm{SiO}_{2}(\mathrm{C})\right.$ catalyst).

The covered catalysts were successfully tested in the hydrogenation of glucose into sorbitol. In comparison with uncovered catalyst, it was demonstrated that the diffusion of reactants/products through the mesoporous layer was possible to reach the underlying active phase. Moreover, the stability of protective silica layers was improved in organic medium at high temperature as confirmed by XPS. The solvent also had a strong influence on the catalysts performance: the conversion being doubled when moving from water to ethanol as solvent. Finally, the selectivity of the studied reaction was influenced by the silica layers' structure: the larger the pores, the higher the selectivity.

Preliminary tests in the hydrolytic hydrogenation of cellobiose were undertaken as well. These revealed that in the absence of acid sites, cellobiose is mainly converted into cellobitol (disaccharide hydrogenation product). This underlines the accessibility of ruthenium nanoparticles despite the protective silica layer and the need for strong acid sites to perform the hydrolysis in organic polar medium. On the contrary, when acidic material was added (heterogeneous acid catalyst consisting of sulfonic acid groups grafted on carbon black), sorbitol was formed, corresponding to the subsequent hydrogenation and hydrolysis steps from cellobiose. Therefore, the protected catalyst is still active in this combination one pot system. All these results prove that by using the present methodology, 
protected catalysts with good performances in model reactions for biomass valorization could be easily prepared, which opens the door to many studies with multifunctional catalytic systems.

Supplementary Materials: The following are available online at http://www.mdpi.com/2073-4344/10/2/149/s1, Figure S1: XPS Ru3p spectra for (a) $\mathrm{Ru} / \mathrm{CB},(\mathbf{b}) \mathrm{Ru} / \mathrm{CB} @ \mathrm{SiO}_{2}(\mathrm{C})$, and (c) $\mathrm{Ru} / \mathrm{CB}_{\mathrm{SSiO}}(\mathrm{P})$ catalysts. Figure S2: Pores size distribution obtained by DFT and BJH methods for (a) $\mathrm{Ru} / \mathrm{CB}_{\mathrm{CSiO}}(\mathrm{C})$ and $(\mathbf{b}) \mathrm{Ru} / \mathrm{CB}_{\mathrm{SSiO}}(\mathrm{P})$ materials. Figure S3: SEM-EDX analyses of (a) $\mathrm{Ru} / \mathrm{CB},(\mathbf{b}) \mathrm{Ru} / \mathrm{CB} @ \mathrm{SiO}_{2}(\mathrm{C})$, and (c) $\mathrm{Ru} / \mathrm{CB} @ \mathrm{CiO}_{2}(\mathrm{P})$ catalysts. Figure S4: TEM images of (a) $\mathrm{CB} @ \mathrm{SiO}_{2}(\mathrm{C})$ and $(\mathbf{b}) \mathrm{CB}_{\mathrm{CS}} \mathrm{O}_{2}(\mathrm{P})$ covered materials. Table S1: Elemental analysis by ICP of $\mathrm{Ru} / \mathrm{CB} @ \mathrm{SiO}_{2}(\mathrm{C})$ and $\mathrm{Ru} / \mathrm{CB} @ \mathrm{SiO}_{2}(\mathrm{P})$ catalysts (wt \%). Table S2: XPS analyses (at \%) of covered catalysts before and after catalytic tests in pure water (W) or ethanol-water mixture (W/E). Table S3: Comparison of normalized activity values with catalysts from literature. Figure S5: (a) Nitrogen adsorption-desorption isotherms at $77 \mathrm{~K}$ and pores size distributions from (b) BJH and (c) DFT for $\mathrm{Ru} / \mathrm{CB} @ \mathrm{SiO}_{2}(\mathrm{P})$ catalyst after a catalytic test.

Author Contributions: Conceptualization and methodology-T.H., V.D. and S.H. (Sophie Hermans); experiment design, acquisition of data and analyses-T.H., S.H. (Sharon Hubert) and S.C.; writing-original draft preparation-T.H.; writing-review and editing-T.H., V.D. and S.H. (Sophie Hermans). All authors have read and agreed to the published version of the manuscript.

Funding: This research was funded by FRS-FNRS and UCLouvain.

Acknowledgments: We are grateful to Jean-François Statsijns for technical assistance and Matthieu Da Costa (Ghent University) for HPLC measurements. We also thank the IMERYS GRAPHITE \& CARBON (Switzerland) firm for generous donations of carbon black.

Conflicts of Interest: The authors declare no conflict of interest.

\section{References}

1. Brethauer, S.; Studer, M.H. Biochemical conversion processes of lignocellulosic biomass to fuels and chemicals-A review. Chimia (Aarau) 2015, 69, 572-581. [CrossRef] [PubMed]

2. Zhou, C.; Xia, X.; Lin, C.; Tong, D.; Beltramini, J. Catalytic conversion of lignocellulosic biomass to fine chemicals and fuels. Chem. Soc. Rev. 2011, 40, 5588-5617. [CrossRef] [PubMed]

3. Climent, M.J.; Corma, A.; Iborra, S. Conversion of biomass platform molecules into fuel additives and liquid hydrocarbon fuels. Green Chem. 2014, 16, 516-547. [CrossRef]

4. Zhang, Y.-H.P.; Lynd, L.R. Toward an aggregated understanding of enzymatic hydrolysis of cellulose: Noncomplexed cellulase systems. Biotechnol. Bioeng. 2004, 88, 797-824. [CrossRef] [PubMed]

5. Wang, Y.; Rong, Z.; Wang, Y.; Wang, T.; Du, Q.; Wang, Y.; Qu, J. Graphene-based metal/acid bifunctional catalyst for the conversion of levulinic acid to $\gamma$-valerolactone. ACS Sustain. Chem. Eng. 2017, 5, 1538-1548. [CrossRef]

6. Haynes, T.; Ersen, O.; Dubois, V.; Desmecht, D.; Nakagawa, K.; Hermans, S. Protecting a Pd/CB catalyst by a mesoporous silica layer. Appl. Catal. B Environ. 2019, 241, 196-204. [CrossRef]

7. Xiong, H.; Pham, H.N.; Datye, A.K. Hydrothermally stable heterogeneous catalysts for conversion of biorenewables. Green Chem. 2014, 16, 4627-4643. [CrossRef]

8. Yang, H.; Zhang, G.; Hong, X.; Zhu, Y. Silylation of mesoporous silica MCM-41 with the mixture of $\mathrm{Cl}(\mathrm{CH} 2) 3 \mathrm{SiCl} 3$ and $\mathrm{CH} 3 \mathrm{SiCl} 3$ : Combination of adjustable grafting density and improved hydrothermal stability. Microporous Mesoporous Mater. 2004, 68, 119-125. [CrossRef]

9. Castricum, H.L.; Mittelmeijer-Hazeleger, M.C.; Sah, A.; ten Elshof, J.E. Increasing the hydrothermal stability of mesoporous $\mathrm{SiO} 2$ with methylchlorosilanes-A "structural" study. Microporous Mesoporous Mater. 2006, 88, 63-71. [CrossRef]

10. Karpov, S.I.; Roessner, F.; Selemenev, V.F.; Belanova, N.A.; Krizhanovskaya, O.O. Structure, hydrophobicity, and hydrothermostability of MCM-41 organo-inorganic mesoporous silicates silylated with dimethoxydimethylsilane and dichloromethylphenylsilane. Russ. J. Phys. Chem. A 2013, 87, 1888-1894. [CrossRef]

11. Ribeiro Carrott, M.M.L.; Conceição, F.L.; Lopes, J.; Carrott, P.J.; Bernardes, C.; Rocha, J.; Ramôa Ribeiro, F. Comparative study of Al-MCM materials prepared at room temperature with different aluminium sources and by some hydrothermal methods. Microporous Mesoporous Mater. 2006, 92, 270-285. [CrossRef]

12. Russo, P.A.; Carrott, M.M.L.R.; Carrott, P.J.M. Effect of hydrothermal treatment on the structure, stability and acidity of $\mathrm{Al}$ containing MCM- 41 and MCM- 48 synthesised at room temperature. Colloids Surf. A Physicochem. Eng. Asp. 2007, 310, 9-19. [CrossRef] 
13. Li, Y.; Yang, Q.; Yang, J.; Li, C. Mesoporous aluminosilicates synthesized with single molecular precursor $(\mathrm{sec}-\mathrm{BuO})_{2} \mathrm{AlOSi}(\mathrm{OEt})_{3}$ as aluminum source. Microporous Mesoporous Mater. 2006, 91, 85-91. [CrossRef]

14. Haynes, T.; D’hondt, T.; Morritt, A.L.; Khimyak, Y.Z.; Desmecht, D.; Dubois, V.; Hermans, S. Mesoporous aluminosilicate nanofibers with a low $\mathrm{Si} / \mathrm{Al}$ ratio as acidic catalyst for hydrodeoxygenation of phenol. ChemCatChem 2019, 11, 4054-4063. [CrossRef]

15. Shuai, L.; Luterbacher, J. Organic solvent effects in biomass conversion reactions. ChemSusChem 2016, 9, 133-155. [CrossRef]

16. Gallo, J.M.R.; Alonso, D.M.; Mellmer, M.A.; Dumesic, J.A. Production and upgrading of 5-hydroxymethylfurfural using heterogeneous catalysts and biomass-derived solvents. Green Chem. 2013, 15, 85-90. [CrossRef]

17. Gu, Y.; Jérôme, F. Bio-based solvents: An emerging generation of fluids for the design of eco-efficient processes in catalysis and organic chemistry. Chem. Soc. Rev. 2013, 42, 9550-9570. [CrossRef]

18. Mellmer, M.A.; Martin Alonso, D.; Luterbacher, J.S.; Gallo, J.M.R.; Dumesic, J.A. Effects of $\gamma$-valerolactone in hydrolysis of lignocellulosic biomass to monosaccharides. Green Chem. 2014, 16, 4659-4662. [CrossRef]

19. Kimura, H.; Yoshida, K.; Uosaki, Y.; Nakahara, M. Effect of water content on conversion of D-cellobiose into 5-hydroxymethyl-2-furaldehyde in a dimethyl sulfoxide-water mixture. J. Phys. Chem. A 2013, 117, 10987-10996. [CrossRef]

20. Deng, W.; Tan, X.; Fang, W.; Zhang, Q.; Wang, Y. Conversion of cellulose into sorbitol over carbon nanotube-supported ruthenium catalyst. Catal. Lett. 2009, 133, 167-174. [CrossRef]

21. Adsuar-García, M.; Flores-Lasluisa, J.; Azar, F.; Román-Martínez, M. Carbon-black-supported Ru catalysts for the valorization of cellulose through hydrolytic hydrogenation. Catalysts 2018, 8, 572. [CrossRef]

22. Zhou, L.; Liu, Z.; Bai, Y.; Lu, T.; Yang, X.; Xu, J. Hydrolysis of cellobiose catalyzed by zeolites-The role of acidity and micropore structure. J. Energy Chem. 2016, 25, 141-145. [CrossRef]

23. Peña, L.; Ikenberry, M.; Ware, B.; Hohn, K.L.; Boyle, D.; Sun, X.S.; Wang, D. Cellobiose hydrolysis using acid-functionalized nanoparticles. Biotechnol. Bioprocess Eng. 2011, 16, 1214-1222. [CrossRef]

24. Bootsma, J.A.; Shanks, B.H. Cellobiose hydrolysis using organic-inorganic hybrid mesoporous silica catalysts. Appl. Catal. A Gen. 2007, 327, 44-51. [CrossRef]

25. Cortright, R.D.; Davda, R.R.; Dumesic, J.A. Hydrogen from catalytic reforming of biomass-derived hydrocarbons in liquid water. Nature. 2002, 418, 964-967. [CrossRef]

26. Huber, G.W.; Chheda, J.N.; Barrett, C.J.; Dumesic, J.A. Production of liquid alkanes by aqueous-phase processing of biomass-derived carbohydrates. Science 2005, 308, 1446-1450. [CrossRef]

27. Kamm, B. Production of platform chemicals and synthesis gas from biomass. Angew. Chem. Int. Ed. 2007, 46, 5056-5058. [CrossRef]

28. Isikgor, F.H.; Becer, C.R. Lignocellulosic biomass: A sustainable platform for the production of bio-based chemicals and polymers. Polym. Chem. 2015, 6, 4497-4559. [CrossRef]

29. Kruk, M.; Jaroniec, M.; Ko, C.H.; Ryoo, R. Characterization of the porous structure of SBA-15. Chem. Mater. 2000, 12, 1961-1968. [CrossRef]

30. Kruk, M.; Jaroniec, M.; Sayari, A. Application of large pore MCM-41 molecular sieves to improve pore size analysis using nitrogen adsorption measurements. Langmuir 1997, 13, 6267-6273. [CrossRef]

31. Quantachrome Instruments. Pore Size Analysis by Gas Adsorption and the Density Functional Theory. 2018. AZoM, viewed 27 August 2019. Available online: https://www.azom.com/article.aspx?ArticleID=5189 (accessed on 27 August 2019).

32. Kusserow, B.; Schimpf, S.; Claus, P. Hydrogenation of glucose to sorbitol over nickel and ruthenium catalysts. Adv. Synth. Catal. 2003, 345, 289-299. [CrossRef]

33. Tronci, S.; Pittau, B. Conversion of glucose and sorbitol in the presence of $\mathrm{Ru} / \mathrm{C}$ and $\mathrm{Pt} / \mathrm{C}$ catalysts. $R S C A d v$. 2015, 5, 23086-23093. [CrossRef]

34. Zhang, J.; Lin, L.; Zhang, J.; Shi, J. Efficient conversion of D-glucose into D-sorbitol over MCM-41 supported Ru catalyst prepared by a formaldehyde reduction process. Carbohydr. Res. 2011, 346, 1327-1332. [CrossRef] [PubMed]

35. Romero, A.; Nieto-Márquez, A.; Alonso, E. Bimetallic Ru:Ni/MCM-48 catalysts for the effective hydrogenation of D-glucose into sorbitol. Appl. Catal. A Gen. 2017, 529, 49-59. [CrossRef]

36. Beck, R.E.; Schultz, J.S. Hindered diffusion in microporous membranes with known pore geometry. Science 1970, 170, 1302-1305. [CrossRef] 
37. Ravenelle, R.M.; Schüßler, F.; D’Amico, A.; Danilina, N.; van Bokhoven, J.A.; Lercher, J.A.; Jones, C.W.; Sievers, C. Stability of zeolites in hot liquid water. J. Phys. Chem. C 2010, 114, 19582-19595. [CrossRef]

38. Zhao, D. Triblock copolymer syntheses of mesoporous silica with periodic 50 to 300 angstrom pores. Science 1998, 279, 548-552. [CrossRef]

39. Pollock, R.A.; Gor, G.Y.; Walsh, B.R.; Fry, J.; Ghampson, I.T.; Melnichenko, Y.B.; Kaiser, H.; DeSisto, W.J.; Wheeler, M.C.; Frederick, B.G. Role of liquid vs. vapor water in the hydrothermal degradation of SBA-15. J. Phys. Chem. C 2012, 116, 22802-22814. [CrossRef]

40. Negahdar, L.; Oltmanns, J.U.; Palkovits, S.; Palkovits, R. Kinetic investigation of the catalytic conversion of cellobiose to sorbitol. Appl. Catal. B Environ. 2014, 147, 677-683. [CrossRef]

41. Carlier, S.; Hermans, S. Highly efficient and recyclable catalysts for cellobiose hydrolysis: Systematic comparison of carbon nanomaterials functionalized with benzyl sulfonic acids. Front. Chem. 2020. submitted.

42. Zhou, L.; Liu, Z.; Shi, M.; Du, S.; Su, Y.; Yang, X.; Xu, J. Sulfonated hierarchical H-USY zeolite for efficient hydrolysis of hemicellulose/cellulose. Carbohydr. Polym. 2013, 98, 146-151. [CrossRef] [PubMed]

43. Liu, Y.; Xiao, W.; Xia, S.; Ma, P. $\mathrm{SO}_{3} \mathrm{H}$-functionalized acidic ionic liquids as catalysts for the hydrolysis of cellulose. Carbohydr. Polym. 2013, 92, 218-222. [CrossRef] [PubMed]

44. Hu, L.; Li, Z.; Wu, Z.; Lin, L.; Zhou, S. Catalytic hydrolysis of microcrystalline and rice straw-derived cellulose over a chlorine-doped magnetic carbonaceous solid acid. Ind. Crop. Prod. 2016, 84, 408-417. [CrossRef]

45. Suganuma, S.; Nakajima, K.; Kitano, M.; Yamaguchi, D.; Kato, H.; Hayashi, S.; Hara, M. Hydrolysis of cellulose by amorphous carbon bearing $\mathrm{SO}_{3} \mathrm{H}, \mathrm{COOH}$, and $\mathrm{OH}$ groups. J. Am. Chem. Soc. 2008, 130, 12787-12793. [CrossRef]

46. Rinaldi, R.; Schüth, F. Acid hydrolysis of cellulose as the entry point into biorefinery schemes. ChemSusChem 2009, 2, 1096-1107. [CrossRef]

47. Soisangwan, N.; Gao, D.-M.; Kobayashi, T.; Khuwijitjaru, P.; Adachi, S. Kinetic analysis for the isomerization of cellobiose to cellobiulose in subcritical aqueous ethanol. Carbohydr. Res. 2016, 433, 67-72. [CrossRef]

48. Gao, D.M.; Kobayashi, T.; Adachi, S. Production of keto-disaccharides from aldo-disaccharides in subcritical aqueous ethanol. Biosci. Biotechnol. Biochem. 2016, 80, 998-1005. [CrossRef]

49. Fang, B.; Chaudhari, N.K.; Kim, M.-S.; Kim, J.H.; Yu, J.-S. Homogeneous deposition of platinum nanoparticles on carbon black for proton exchange membrane fuel cell. J. Am. Chem. Soc. 2009, 131, 15330-15338. [CrossRef]

(C) 2020 by the authors. Licensee MDPI, Basel, Switzerland. This article is an open access article distributed under the terms and conditions of the Creative Commons Attribution (CC BY) license (http://creativecommons.org/licenses/by/4.0/). 